\title{
Assessment of Instruction Delivery in Distance Education in Nigeria
}

\section{Dr. Ebisine, Sele Sylvester}

Department of Mathematics, College of Education, Warri,Delta State,Nigeria

Email: ebisineselesylvester@yahoo.com

\author{
Dr. Ajuar, N. Helen
}

Department of Psychology, College of Education, Warri, Delta State, Nigeria

\section{Doi:10.5901/mjss.2015.v6n4s1p95}

\begin{abstract}
The present study aimed at assessing the level of instruction delivery in distance education in Nigeria. Two research questions and two hypotheses guided the study. A total of 320 distance learners were randomly drawn from five National Open University of Nigeria (NOUN) centres. The study focused on the sufficiency of learning media and the extent of preparedness of distance institutions in the adoption of internet-based system in instruction delivery process. Mean and standard deviation was used to answer the research questions while t-test statistics was employed to test the hypotheses at 0.05 level of significance. The result of the study showed that there are sufficient learning media and moderate extent of preparedness in the adoption of internet-based system in distance learning institutions. Based on the findings, some recommendations were made at the end of the study.
\end{abstract}

Keywords: Assessment, Instruction Delivery, Distance Education, Learning Media and Internet Based System

\section{Introduction}

The concept of distance education describes all form of education in which the learner is normally in a different place from the teacher (Moore, 1992). According to Moore and Tait (2002) distance education focuses on opening access to education and training provision, freeing learners from the constraints of time and place, and flexible learning opportunities to individuals and groups of learners. They noted that distance learning is one of the most rapidly growing field of education, and its potential impact on all education delivery system has been greatly accentuated through the development of Internet-based information technologies, and in particular the World Wide Web. Therefore, distance education is an industrialized form of teaching and learning which have to undertake directly a number of quasi-industrial processes. The distance education course can be distributed over a wide geographical area to a much larger audience than conventional instruction. Properly organized distance learning education system arrange for interpersonal, studenttutor interaction through correspondence or print-based communication, tele-conferencing or other technologies and even occasional face-to-face meetings. For this the learner in distance education may receive more individual instruction than in conventional education. According to Omorogbe and Aghaboren (2009), instructional delivery in Nigerian distance learning institutions like other countries began mainly with print medium by mailing (correspondence), then to face-to-face tutoring using the print medium. The mode of instruction delivery in most countries, they observed has long moved from the use of the print medium as the only and main instruction delivery medium to the application of Information and Communication Technology (ICT) in the learning process, continuing they said, instruction delivery is now carried out through Audio and Video CD, CD-ROM, Video conferencing, Audio conferencing, e-learning/internet usage.

However, despite the fact that distance education method of instruction delivery has moved from the correspondence to the internet-based system where multimedia (text, audio, video and computer-based) materials in electronic format are delivered to individuals through computers, along with access to databases and electronic libraries, and which enable teacher-student and student-student, one-to-one, one-to-many, and many-to-many interactions, synchronously or asynchronously, through e-mail, computer and conferences, bulletin boards among others (Moore \& Tait, 2002), it would be necessary to assess the education media employed in instruction delivery and the extent of preparedness by Nigeria in adopting internet-based system in the instruction delivery process of her distance learning institutions.

Assessment is an essential component of programme improvement and renewal and long-term success. As noted 
by Willis (1993) even the best designed or adapted distance delivered course will likely require revision. According to Verduin and Clark (1991) good evaluation will also assist distance educators in thinking about what they are trying to do and achieve as they implement programmes and activities. Continued development in distance education is essential and evaluation can reveal what is effective and what is not. Assessment resulting in programme refinements is highly important if quality is to be achieved and maintained.

This paper, therefore, assessed education media used in instruction delivery and the extent of preparedness in Nigeria in adopting internet-based systems in instruction delivery in distance learning education.

\section{Review of Related Literature}

\subsection{Assessment}

Assessment is a synonym for evaluation (Bell \& Cowre, 2006). To them, it requires both a description of any judgment regarding whatever phenomenon is being assessed, be it students learning, teacher's teaching, school climate, state level commitment and support or any other education related construct. Obioma (1991) defined assessment as the process of using the result obtained from measurement to take relevant decisions about a programme being assessed. Assessment according to Chauban cited in Anikweze (2005) is the practical application of measurement. And just as all testing could be subsumed under assessment, so could all measurement could be subsumed under assessment. Posavae and Carey (2002) remarked that assessment is a collection of methods, skills and sensitivities necessary to determine whether a human service is needed and likely to be used, whether it is conducted as planned, and whether the human service actually does help people. Assessment of human service programmes are conducted to answer questions and address issues that are raised by stakeholders. A common method of categorizing programme assessment according to Scriven (1981) is by whether they are formative or summative or a combination of the two. Formative evaluations focus more on process and feedback to determine the extent to which the program is operating as intended. The idea behind the formative evaluation is to ensure that the course or instructional product is meeting its stated goals as efficiently and effectively as possible and that the program is being implemented as planned. The focus, therefore, is on academic quality management. Summative evaluations, on the other hand, seek to discover if the program made a difference. That is, the emphasis is on determining the results or outcomes of the program. Summative evaluations are often used for accountability purposes.

\subsection{Distance Education}

Distance education is any educational process in which all or most of the teaching is conducted by someone removed in space and/or time from the learner, with the effect that all or most of the communication between teachers and learners is through an artificial medium, either electronic or print (Moore \& Tait, 2002). Jegede (2003) presented distance education as education provided by a mode other than the conventional (fact-to-face) method whose goals are similar to and just as noble and practical to those of on-campus and full time conventional education. The six basic elements enunciated by Keegan (1993) as the main characteristic feature of a distance learning institution include:

1. the separation of teacher from learner

2. the influence of an education authority

3. the use of communication technologies

4. two way communication between tutors and learners

5. possibility of face-to-face meetings for tutorials and

6. use of industrialized process. (COL, 2000)

The National Teachers' Institute (NTI) started as a distance learning institution in 1976 (as the first dedicated distance learning institution) with the support of UNESCO. It began by training Grade Two Teachers (TC II). Ahmadu Bello University $(\mathrm{ABU})$ also started its distance education through a training programme known as Teachers-in-Service Education Programme (TISEP) for Grades Three and Two teachers and later the Nigerian Certificate in Education (NCE).

The National Open University of Nigeria (NOUN), was establish in July, 1983, by the then Federal Government of Nigeria by an Act of the National Assembly as the first distance learning tertiary institution in Nigeria when the demand for education in Nigeria could no longer be met by the conventional system of education. The establishment of distance education programmes is in conformity with section $40(\mathrm{a})$ of the National Policy on Education which states that:

Maximum effort will be made to enable those who can benefit from higher education to be given access to it. Such access may be through universities or correspondence courses, or open universities, or part time and work study 
programmes.

These systems are being used to solve problems in many countries. Some of the successful ones are, The British Open University; the Correspondence Course Unit (CCU) at the University of Nairobi, Kenya; Mauritius College of the air, Botswana Extension College.

\subsection{Purpose of the Study}

The purpose of this study was to assess the education media used in instruction delivery in education in Nigeria. Specifically, the study:

1. determine whether the learning media used in the distance institutions are sufficient.

2. ascertain the extent of preparedness of distance institutions in adoption of internet-based systems in instruction delivery process.

\subsection{Research Questions}

1. Are the learning media used in the distance institutions sufficient?

2. What is the extent of preparedness of distance institutions in adoption of internet-based systems in instruction delivery process?

\subsection{Hypotheses}

1. There is no statistically significant $(p<0.05)$ difference in the mean ratings of male and female distance education students as regards the sufficiency of learning media used in the distance institutions.

2. There is no statistically significant $(p<0.05)$ difference in the mean ratings of male and female distance education students as regards the extent of preparedness of distance institutions in adoption of internet based systems in instruction delivery process.

\section{Methodology}

The investigation employed the descriptive survey research design. The descriptive survey was used to determine the sufficiency of learning media and the extent of preparedness of distance institutions in adoption of internet-based systems in instruction delivery process.

The sample of the study comprised 320 undergraduate students from five (5) National Open University of Nigeria (NOUN) centres. The researcher adopted a stratified disproportionate random sampling procedure to select five (5) NOUN centres from the entire centres in Nigeria. From each of the five centres, 64 undergraduate distance learners were selected through balloting by replacement. This gives a total of three hundred and twenty (320) distance learners.

The instrument for data collection is a researcher developed questionnaire titled: Assessment of Instruction Delivery in Distance Education (AIDDE). The questionnaire was divided into two sections, A and B. Section A sought information on the personal data of the respondents. While Section B was designed to elicit responses from the respondents as regards their opinion on the sufficiency of learning media and the extent of preparedness of distant institutions in adoption of internet-based systems in instruction delivery process. The instrument was structured on a four point Likert scale of Strongly Agree (SA), Agree (A), Disagree (D) and Strongly Disagree (SD) with assigned weight of 4, 3,2 , and 1 point respectively. For each respondent, an overall mean score for all the items were computed. An overall mean score of 2.5 and above showed that there are sufficient learning media and a high level of preparedness of distance institutions in the adoption of internet-based systems in instruction delivery process. An overall mean score of below 2.5 showed that there are no sufficient learning media and a low level of preparedness of distance institutions in the adoption of internet-based systems in instruction delivery process. While the t-test statistics was used to test the hypotheses formulated at 0.05 level of significance.

\section{Results}

Result of the study are presented based on the research questions and corresponding hypotheses. Table 1 presents the data elicited by research question 1. 


\begin{tabular}{|c|l|c|c|c|c|c|c|}
\hline \multirow{2}{*}{ S/N } & \multirow{2}{*}{ Items } & \multicolumn{3}{|c|}{ Male (N = 220) } & \multicolumn{3}{c|}{ Female (N = 100) } \\
\cline { 3 - 8 } & & Mean & SD & Remark & Mean & SD & Remark \\
\hline 1. & Print Media & 3.06 & 0.92 & Agree & 3.03 & 0.97 & Agree \\
\hline 2. & Radio Programme & 2.28 & 0.99 & Disagree & 2.14 & 0.88 & Disagree \\
\hline 3. & Audio Tapes & 3.01 & 1.07 & Agree & 3.07 & 0.91 & Agree \\
\hline 4. & Instructional e-mail & 3.12 & 0.83 & Agree & 2.96 & 1.06 & Agree \\
\hline 5. & Audio CD & 3.03 & 0.94 & Agree & 3.06 & 0.92 & Agree \\
\hline 6. & Video CD & 3.01 & 1.07 & Agree & 3.10 & 0.91 & Agree \\
\hline 7. & Video Conferencing & 3.07 & 0.91 & Agree & 3.03 & 0.94 & Agree \\
\hline 8. & Audio Conferencing & 3.10 & 0.91 & Agree & 3.06 & 0.92 & Agree \\
\hline 9. & Internet enabled learning/ e-learning & 3.06 & 0.92 & Agree & 3.12 & 0.83 & Agree \\
\hline 10. & Facsmile (fax) & 3.03 & 0.97 & Agree & 3.01 & 1.07 & Agree \\
\hline 11. & Instructional Computer Programme & 3.10 & 0.91 & Agree & 3.07 & 0.91 & Agree \\
\hline 12. & Television Programme & 2.07 & 0.93 & Disagree & 2.25 & 0.95 & Disagree \\
\hline
\end{tabular}

The table 1 above shows the mean responses of the respondents on determining whether the learning media used in distance institutions are sufficient. Out of the twelve items stated in the table, ten items were agreed to by the respondents as they had mean ratings above the 2.50 cut-off point, while two were disagreed to as they had mean ratings below the 2.50 cut-off point. It is therefore in the respondents' opinion that print media, audio tapes, instructional e-mail, audio $C D$, video $C D$, video conferencing, audio conferencing, internet enabled learning/e-learning, facsimile (fax) and instructional computer programme are all sufficient learning media used in distance education, while radio programme and television programme are not.

Table 2 presents the data elicited by research question 2

Table 2: Mean responses ascertaining the extent of preparedness of distance institutions in adoption of internet-based systems in instruction delivery process

\begin{tabular}{|c|l|c|c|c|c|c|c|}
\hline \multirow{2}{*}{ S/N } & \multirow{2}{*}{ Items } & \multicolumn{2}{|c|}{ Male (N = 220) } & \multicolumn{3}{c|}{ Female (N= 100) } \\
\cline { 3 - 8 } & & Mean & SD & Remark & Mean & SD & Remark \\
\hline 1. & Students have working knowledge of the computer and ICT & 3.12 & 0.83 & Agree & 2.96 & 1.06 & Agree \\
\hline 2. & $\begin{array}{l}\text { Students have unequal financial ability to own personal computers } \\
\text { and subscribe for internet subscription fees }\end{array}$ & 3.09 & 0.68 & Agree & 3.01 & \multirow{2}{*}{1.07} & \multirow{2}{*}{ Agree } \\
\hline 3. & Students preference for print media to electronic media & 3.03 & 0.97 & Agree & 3.06 & 0.92 & Agree \\
\hline 4. & There is provision of ICT equipment for learning in my school & 2.10 & 0.92 & Disagree & 2.16 & 0.97 & Disagree \\
\hline 5. & Facilitators/Tutors possess working knowledge of ICT in my school & 3.05 & 0.89 & Agree & 3.10 & 0.91 & Agree \\
\hline 6. & Problem in the provision of electricity & 3.03 & 0.97 & Agree & 2.96 & 1.06 & Agree \\
\hline
\end{tabular}

The table 2 above shows the mean responses of the respondents on ascertaining the extent of preparedness of distance institutions in adoption of internet-based systems in instruction delivery process. Out of the six items stated in the table, five items were agreed to by the respondents as they had mean ratings above the 2.50 cut-off point, while one were disagreed to as it had mean ratings below the 2.50 cut-off point. It is therefore in the respondents' opinion that students have working knowledge of the computer and ICT, they have unequal financial ability to own personal computers and subscribe for internet subscription fees, they are convenient with the print media than the electronic media, there is no provision of ICT equipment for learning in their schools, the facilitators/tutors in their schools possess working knowledge of ICT and there is problem in the provision of electricity.

Table 3 presents the data elicited by hypothesis 1

Table 3: T-Test analysis of difference in the mean ratings of male and female distance education students as regards the sufficiency of learning media used in the distance institutions

\begin{tabular}{|c|c|c|c|c|c|c|c|}
\hline Students & N & Mean & SD & DF & T-Cal. & T-Tab. & Alpha Level \\
\hline Male & 220 & 34.94 & 11.37 & \multirow{2}{*}{318} & 0.03 & 1.96 & 0.05 \\
\hline Female & 100 & 34.90 & 11.27 & & & & \\
\hline
\end{tabular}

Table 3 above shows t-test analysis of difference in the mean ratings of male and female distance education students as regards the sufficiency of learning media used in the distance institutions, and it is revealed that t-calculated is 0.03 , while 
the tabulated t-value is 1.96 at an alpha level of 0.05 . Thus, there is no statistically significant difference in the mean ratings of male and female distance education students as regards the sufficiency of learning media used in the distance institutions.

Table 4 presents the data elicited by hypothesis 2

Table 4: T-test analysis of difference in mean ratings of male and female distance education students as regards the extent of preparedness of distance institutions in adoption of internet based systems in instruction delivery process

\begin{tabular}{|c|c|c|c|c|c|c|c|}
\hline Students & N & Mean & SD & DF & T-Cal. & T-Tab. & Alpha Level \\
\cline { 1 - 5 } Male & 220 & 17.42 & 5.27 & \multirow{2}{*}{318} & 0.24 & \multirow{2}{*}{1.96} & \multirow{2}{*}{0.05} \\
\hline Female & 100 & 17.25 & 5.99 & & & \\
\hline
\end{tabular}

Table 4 above shows t-test analysis of difference in the mean ratings of male and female distance education students as regards the extent of preparedness of distance institutions in adoption of internet based systems in instruction delivery process, and it is revealed that t-calculated is 0.24 , while the tabulated t-value is 1.96 at an alpha level of 0.05 . Thus, there is no statistically significant difference in the mean ratings of male and female distance education students as regards the extent of preparedness of distance institutions in adoption of internet based systems in instruction delivery process.

\section{Discussion}

The result of the present study has shown that most of the learning media used in the distance institutions in Nigeria are sufficient. This simply means that of all the 12 items on media, the distance institutions adequately provide ten of them. The rest two are insufficient. This is in agreement with Butcher (2003) that the print media predominate globally in the delivery of distance education institutions/facilitators/tutors and distance learners. This finding also agreed with that of Aderinonye (1984) in his findings discovered that a larger percentage of learners are reached through the non-print media. Thus, a major characteristic feature of distance education is in the use of variety of media for communication (Barron, 1999).

Furthermore, the result of the study also indicated that there is moderate extent of preparedness of distance institutions in adoption of internet-based systems in instruction delivery process. This is because the response made by the learners showed that there is lack of ICT equipment and problems with power supply. This finding agreed with that of Yusuf and Falade (2006) in Omorogbe and Aghagboren (2009) that the predominantly used media are print media. According to them, the reason why modern technology media was not used was due to unavailability of modern technology media, lack of experts to operate the equipment among other factors.

The result of this study also showed that there is no statistically significant difference in the mean ratings of male and female distance education students as regards sufficiency of learning media and the extent of preparedness of distance education institutions in adoption of internet-based system in instruction delivery process. This finding agreed with that of Lockee, Moore and Burton (2001) that revealed no significant difference between the face-to-face instruction and distance-delivered instruction. This showed that not all distance education programme are equally effective. Nigeria as a country in the past two administration (1999 - 2007) has experienced a considerable level of advancement in ICT, but this is yet to be channeled into and access by the open distance institutions in the country due to the lack of effort by the government (Omorogbe \& Aghagboren, 2009).

\section{Conclusion and Recommendations}

The study set out to assess the education media used in instruction delivery and the extent of preparedness in adapting internet-based system in instruction delivery in distance learning institutions in Nigeria. The result showed that there are sufficient learning media and moderate extent of preparedness in the adoption of internet-based system in distance learning institutions. It is therefore recommended that:

1. Government should finance the installation of computer technology system in the distance learning institutions.

2. There should be adequate provision of ICT facilities to enable the learners use their CDs.

3. Government should ensure there is stable electricity supply. 


\section{References}

Aderinoye, R.A. (1984). Literacy by television: The television service of Oyo state lagun experiment. Unpublished M.Ed. Dissertation, University of Ibadan, Nigeria.

Anikweze, C.M. (2005). Assessment and the further of schooling and learning. A paper presented at the $31^{\text {st }}$ Annual Confrence of the International Association for Educational Assessment, Abuja, Nigeria, $4^{\text {th }}-9^{\text {th }}$ September.

Barron, A. (1999). Introduction centre for instructional technology. In a Teacher's Guide to Distance Learning.

Bell, B. \& Cowre, B. (2001). Formative Assessment and Science Education. Dordrecht - Netherlands: Kluwer Academic Publisher.

Butcher, N. (2003). Technological infrastructure and use of ICT in Africa: An overview. Association for the Development of Education in Africa (ADEA).

Common Wealth of Learning (COL) (2000). An Introduction to Open Distance Learning.

Federal Republic of Nigeria (1981). National Policy on Education. Rev. Lagos: NERC.

Jegede, O. (2002). Taking the distance out of Higher Education in $21^{\text {st }}$ Century Nigeria. A paper presented at the Federal Polytechnic, Oko, Anambra State, $10^{\text {th }}$ Anniversary Celebration.

Keegan, D. (ed). (1983). Theoretical Principles of Distance Education. London: Rutledge Falmer.

Lockee, B; Moore, M. \& Burton, J. (2001). Old concerns with new distance education research. Educause Quarterly, 2,60 - 62.

Moore, M. \& Tait, A. (2002). Open and Distance Learning: Trends, Policy and Strategy Considerations. Paris: UNESCO.

Moore, M.G. (1992). Distance education at post-secondary level. The Encyclopedia of Higher Education, 2 p. 1097

Nwegbu, M.U. (2001). Distance education in Nigeria: Role of the library. In A.U. Akubue and D. Enyi (Eds) Crises and Challenges in Higher Education in Developing Countries. A Book of Readings. Ibadan: Wisdom Publishers Ltd.

Obioma, G.O. (1991). Concrete models as generators of interest of learning some 3-dimensional shapes. Journal of Science Teachers Association of Nigeria (STAN), 27 (1), $40-46$.

Omorogben, A.D. \& Aghagboren, C.O. (2009). The role of Information and Communication Technology (ICT) in instructional delivery in Open and Distance Education (ODE) in Nigeria. Benin Journal of Education Studies, 19 (1 \& 2); 226 - 237.

Scriven, M.S. (1981). The Logic of Evaluation. Inverness, C.A.: Edgepress.

Verdvin, J.R. \& Clark, T.A. (1991). Distance Education, the Foundation of Effective Practice. San Francisco: Jossey-Bass.

Willis, B. (1993). Instructional Development for Distance Education. Syracuse, NY: Syracuse University. 